\title{
Níveis dietéticos de lisina digestível para frangos de corte machos no período de 1 a 11 dias de idade: desempenho e composição corporal
}

\section{Ana Louise de Toledo $^{1}$, Paula Takeara ${ }^{1}$, Letícia Cardoso Bittencourt ${ }^{1}$, Estela Kobashigawa ${ }^{1}$, Ricardo de Albuquerque ${ }^{2}$, Messias Alves da Trindade Neto $^{2}$}

${ }^{1}$ Mestre em Nutrição Animal pela FMVZ/USP - Pirassununga, SP.

${ }^{2}$ Departamento de Nutrição e Produção Animal da FMVZ/USP - Pirassununga, SP.

RESUMO - Um experimento foi conduzido com o objetivo de avaliar a exigência de lisina digestível para frangos de corte machos da linhagem Ross no período de 1 a 11 dias de idade. Utilizaram-se 1.050 pintos de 1 dia alimentados com cinco dietas, isoenergéticas (2.950 kcal EM/kg) e isoprotéicas (23\% PB), com 1,12; 1,17; 1,22; 1,27 e 1,35\% de lisina digestível, distribuídos em um delineamento em blocos ao acaso com sete repetições e 30 aves por unidade experimental. Realizou-se abate comparativo para determinar a deposição de nutrientes corporais. Observaram-se reduções lineares no peso final, no ganho de peso, no ganho de peso relativo e no consumo de alimento, o que indica provável excesso de aminoácidos na dieta. A composição química corporal não diferiu entre as aves, exceto o conteúdo de cinzas no sangue e nas vísceras, que apresentou resposta quadrática aos níveis de lisina digestível da dieta. Nas taxas de deposição de nutrientes, observou-se redução linear na deposição de água na carcaça. O nível ótimo de lisina digestível para frangos de corte machos de 1 a 11 dias de idade deve ser igual ou inferior a 1,12\%, entretanto, novos estudos devem ser realizados com níveis menores.

Palavras-chave: aminoácido, deposição de nutrientes, exigência, nutrição

\section{Digestible lysine levels in male broiler chicken diets from 1 to 11 days of age: performance and body composition}

\begin{abstract}
An experiment was carried out to evaluate digestible lysine requirement for male broilers chicks of Ross line from 1 to 11 days old. A total of 1050 one day old male chicks were fed with five isoenergetic $(2,950 \mathrm{kcal} \mathrm{ME} / \mathrm{kg})$ and isoproteic $(23 \% \mathrm{CP})$ diets, with digestible lysine levels of 1.12, 1.17, 1.22, 1.27 and $1.35 \%$. A completely randomized bloc design was used with seven replications of 30 birds per experimental unit. A comparative slaughter technique was conducted to determine body nutrients depositions. A decreasing linear effects in final weight, weight gain, relative weight gain and feed intake were observed suggesting a probable amino acid excess in diet. The body chemical composition did not differ among birds, except for blood and offal ashes content, whish shown a quadratic response to digestible lysine levels in the diets. A decreasing linear response was observed for carcass water deposition. The best digestible lysine level for broilers from 1 to 11 days old must be equal to or lower than $1.12 \%$, however further researches must be conducted with lower levels.
\end{abstract}

Key Words: amino acid, nutrient deposition, nutrition, requirement

\section{Introdução}

A preocupação com o uso de dietas pré-iniciais na alimentação de frangos de corte pode ser considerada um avanço da alimentação, visto que as diferenças dos pontos de vista anatomofisiológico e nutricional justificam a adoção de dietas diferenciadas no período inicial, de maior crescimento.

O progresso genético na taxa de crescimento, na conversão alimentar e no rendimento de carcaça estabelece constante desafio à nutrição. Considerando que a expressão fenotípica do potencial genético depende do ambiente e da nutrição, é importante conhecer as exigências nutricionais das aves em processo de melhoramento para obtenção de máximo desempenho.

$\mathrm{Na}$ primeira semana de vida, as exigências dos aminoácidos são elevadas e diminuem com a idade das aves. Determiná-las nas fases pré-inicial e inicial assegura melhor desempenho das aves e redução de custo das dietas. Em virtude do rápido desenvolvimento corporal, da alta taxa metabólica e do baixo consumo de alimento, a lisina suprida em quantidades adequadas garante maior uniformidade do lote de frangos no período inicial de crescimento (Ajinomoto, 2006). 
As exigências em aminoácidos devem estar associadas ao custo da alimentação, pois a proteína é o segundo nutriente mais caro da dieta e representa de 40 a $45 \%$ do custo total da alimentação (Sakomura \& Silva, 1998). A redução protéica tem sido considerada uma das vias de possível melhoria dos custos de produção. O teor protéico da dieta passou a ser definido como o nível ótimo para atender às necessidades em aminoácidos, considerando o custo dos ingredientes utilizados na formulação e o valor das carnes produzidas.

Os aminoácidos industriais lisina, metionina, treonina e triptofano têm significativa participação na aplicabilidade do conceito de proteína ideal para aves. Amparado pela pesquisa, o uso desses ingredientes têm viabilizado a redução do nível de $\mathrm{PB}$ nas dietas sem prejuízo às exigências nutricionais do frango de corte. Portanto, é possível evitar o excesso de aminoácidos, aumentar a eficiência de utilização da proteína e reduzir a poluição ambiental diminuindo a excreção de nitrogênio (Deschepper \& De Groote, 1995; Hurwitz et al., 1998).

O modelo de proteína ideal é constantemente modificado durante o desenvolvimento das aves. A relação entre lisina e os demais aminoácidos essenciais considerada ideal para mantença e crescimento difere conforme as mudanças no peso metabólico e influenciam a exigência em aminoácidos essenciais (Mack et al., 1999). Alguns autores afirmam que o excesso de aminoácidos consumido prejudica o desempenho das aves, eleva o custo de formulação das dietas, incrementa o calor metabólico e contribui para a excreção de nitrogênio, além de causar problemas sanitários relacionados à má qualidade da cama do aviário (Bercovici \& Suida, 1998).

A lisina, apesar de ser o segundo aminoácido limitante, depois da metionina, na alimentação de aves, foi escolhida como aminoácido-referência para o modelo de proteína ideal por ser utilizada quase que exclusivamente para deposição de proteína corporal (Pack, 1995).

Neste estudo, objetivou-se estabelecer o melhor nível de lisina para frangos de corte machos da linhagem Ross no período de 1 a 11 de idade aplicável às condições climáticas da região de Pirassununga-SP.

\section{Material e Métodos}

O experimento foi conduzido Setor de Avicultura da Faculdade de Medicina Veterinária e Zootecnia, Universidade de São Paulo, campus de Pirassununga, entre os dias 29 de agosto e 5 de setembro de 2004, correspondente ao período de 1 a 11 dias de idade das aves. O galpão experi- mental utilizado, construído em alvenaria, é dividido em 36 boxes de 4,25 $\mathrm{m}^{2}$, possui janelas laterais e cortinas para controle da ventilação e temperatura internas. Os boxes dispunham de comedouro tubular, bebedouro pendular, campânula para aquecimento e piso forrado com maravalha.

Em cada extremidade do galpão, foi instalado um termômetro de máxima e mínima, a 1,0 m das aves, para realização de três leituras diárias, determinantes no controle das campânulas e das cortinas laterais no decorrer do estudo.

Foram utilizados 1.050 pintos de um dia, machos da linhagem Ross, com peso inicial médio de 46,4 g, distribuídos em um delineamento em blocos ao acaso com cinco tratamentos, sete repetições e 30 aves por unidade experimental (boxe).

Até os 11 dias de idade, foram fornecidas cinco dietas isoprotéicas (23\% PB) e isoenergéticas (2.950 kcal EM), formuladas com cinco níveis $(1,12 ; 1,17 ; 1,22 ; 1,27$ e 1,35\%) de lisina digestível (Tabela 1), compostas segundo exigências descritas por Rostagno et al. (2000). As dietas foram fornecidas à vontade, com base nas quantidades estabelecidas no manual da linhagem (Agroceres, 2004) para o período de 1 a 11 dias de idade. As sobras foram pesadas para determinação do consumo médio no período.

Foram considerados na avaliação do desempenho o peso final médio, o ganho de peso médio, o ganho de peso relativo, o consumo médio e a conversão alimentar. O ganho de peso relativo foi obtido pela relação entre o ganho de peso e o peso inicial e foi estudada por associar o ganho de peso no período com o peso inicial. Para efeito de correção do consumo médio de alimento, os dados foram corrigidos de acordo com a mortalidade dentro da unidade experimental. Foram calculadas no período a ingestão de lisina, a ingestão de energia metabolizável e a relação lisina digestível:energia metabolizável ingerida. Os dados de ingestão de lisina e energia metabolizável foram obtidos pelo fator entre o consumo médio diário e a composição calculada da dieta.

Na composição química, foram analisadas (AOAC, 1984) as concentrações percentuais de água, PB, lipídeo e cinzas das frações sangue vísceras e carcaça corpo vazio. A partir da composição, foram determinadas as taxas de deposição de água, proteína, lipídeo e minerais na carcaça e no corpo vazio e calculadas as relações proteína:água e proteína:lipídeo.

O abate comparativo foi realizado no primeiro dia do experimento, quando foram abatidas dez aves (pintinhos de um dia), escolhidas aleatoriamente, para separação das frações sangue/vísceras e carcaça. Após processamento e análise química das frações corporais, foram obtidos os valores de proteína, água, lipídeo e cinzas, para determinação 
Tabela 1 - Composições percentual e calculada das dietas fornecidas no período de 1 a 11 dias de idade Table 1 - $\quad$ Percentage and calculated compositions of diets fed from 1 to 11 days old

\begin{tabular}{|c|c|c|c|c|c|}
\hline \multirow[t]{2}{*}{$\begin{array}{l}\text { Ingrediente (\%) } \\
\text { Ingredient }\end{array}$} & \multicolumn{5}{|c|}{$\begin{array}{l}\text { Lisina digestível (\%) } \\
\text { Digestible lysine }\end{array}$} \\
\hline & 1,12 & 1,17 & 1,22 & 1,27 & 1,35 \\
\hline Milho (Corn) & 56,660 & 56,910 & 57,140 & 56,320 & 53,440 \\
\hline Farelo de soja (Soybean meal) & 33,360 & 33,030 & 32,720 & 34,240 & 39,360 \\
\hline Óleo de soja (Soybean oil) & 0,700 & 0,620 & 0,540 & 0,900 & 2,110 \\
\hline Glúten de milho (Corn gluten meal) & 5,000 & 5,000 & 5,000 & 3,840 & 0,260 \\
\hline L-lisina $\mathrm{HCl}$ (L-lysine $\mathrm{HCl}$ ) & 0,132 & 0,232 & 0,308 & 0,334 & 0,320 \\
\hline DL-metionina (DL-methionine) & 0,153 & 0,209 & 0,255 & 0,301 & 0,401 \\
\hline L-treonina (L-threonine) & 0 & 0,004 & 0,042 & 0,074 & 0,123 \\
\hline L-valina (L-valine) & 0 & 0 & 0 & 0 & 0,041 \\
\hline Sal (Salt) & 0,580 & 0,580 & 0,580 & 0,580 & 0,580 \\
\hline Calcário (Limestone) & 1,050 & 1,050 & 1,050 & 1,050 & 1,020 \\
\hline Fosfato bicálcico (Dicalcium phosphate) & 1,910 & 1,910 & 1,910 & 1,910 & 1,890 \\
\hline Cloreto colina (Coline choride) & 0,030 & 0,030 & 0,030 & 0,030 & 0,030 \\
\hline Antioxidante (Antioxidant) & 0,025 & 0,025 & 0,025 & 0,025 & 0,025 \\
\hline Suplemento vitamínico e mineral ${ }^{1}$ (Vitamin and mineral mix) & 0,400 & 0,400 & 0,400 & 0,400 & 0,400 \\
\hline \multicolumn{6}{|l|}{$\begin{array}{l}\text { Composição calculada } \\
\text { Calculated composition }\end{array}$} \\
\hline EM (ME) $(\mathrm{kcal} / \mathrm{kg})$ & 2.950 & 2.950 & 2.950 & 2.950 & 2.950 \\
\hline PB (CP) (\%) & 23,00 & 23,00 & 23,00 & 23,00 & 23,00 \\
\hline Са $(\%)$ & 1,00 & 1,00 & 1,00 & 1,00 & 1,00 \\
\hline P disponível (\%) (Available P) & 0,48 & 0,48 & 0,48 & 0,48 & 0,48 \\
\hline Na $(\%)$ & 0,25 & 0,25 & 0,25 & 0,25 & 0,25 \\
\hline Lisina digestível (\%) (Digestible lysine) & 1,12 & 1,17 & 1,22 & 1,27 & 1,35 \\
\hline Met+cist digestível (\%) (Digestible methionine + cystine) & 0,83 & 0,88 & 0,92 & 0,95 & 1,01 \\
\hline Treonina digestível (\%) (Digestible threonine) & 0,76 & 0,76 & 0,79 & 0,83 & 0,88 \\
\hline Triptofano digestível (\%) (Digestible tryptophan) & 0,23 & 0,23 & 0,23 & 0,28 & 0,26 \\
\hline Leucina digestível (\%) (Digestible leucine) & 2,05 & 2,05 & 2,04 & 1,97 & 1,78 \\
\hline Arginina digestível (\%) (Digestible arginine) & 1,33 & 1,32 & 1,31 & 1,33 & 1,42 \\
\hline Valina digestível (\%) (Digestible valine) & 0,99 & 0,99 & 0,99 & 0,98 & 0,97 \\
\hline Isoleucina digestível (\%) (Digestible isoleucine) & 0,92 & 0,92 & 0,91 & 0,91 & 0,92 \\
\hline
\end{tabular}

${ }^{1}$ Fornece/kg de dieta (provided/kgof diet): ácido fólico (folic acid) - 0,8 mg; BHT - 0,01 mg; bacitracina de zinco (zinc bacitracin) - 50 ppm; halquinol - 18 ppm; $\mathrm{Cu}-8$ ppm; Fe - 50 ppm; I - 0,75 ppm; Mn - 75 ppm; Se - 0,30 ppm; vit. A - 6720 Ul; vit. $B_{1}-1,74$ mg; vit. B $B_{12}-9,60$ mcg; vit. $B_{2}-4,80$ mg; vit. $B_{6}$ 2,49 mg; vit. $\mathrm{D}_{3}-1.600 \mathrm{Ul}$; vit. E, $14 \mathrm{mg}$; vit. K - 1,44 mg; Zn - 70 ppm; niacina (niacin) - 33,60 mg; ácido pantotênico (pantothenic acid) - 12,48 mg; colina (choline) - 313,20 mg; biotina (biotin) - $40 \mathrm{mcg}$.

da composição química e da deposição de nutrientes corporais ao final do período experimental.

Ao final do experimento, duas aves de cada boxe (14 por tratamento) foram escolhidas de acordo com o peso final médio do boxe e abatidas para determinação da composição química e da deposição de nutrientes corporais aos 11 dias de idade.

No abate, adotou-se o método de sangria. O sangue foi coletado em sacos plásticos e as vísceras foram retiradas, esvaziadas, lavadas, escorridas e pesadas junto ao sangue, após identificação. Em seguida, o material (sangue e vísceras) foi pesado e congelado.

Consideraram-se como vísceras todo o trato digestório vazio, os órgãos reprodutores, o coração, o fígado, o baço, o pulmão, as glândulas anexas e a gordura adjacente. Nesta etapa, a carcaça foi definida como a ave desprovida de vísceras e sangue. Considerou-se, portanto, a presença de cabeça, penas e pés. A carcaça, depois de identificada, foi pesada e congelada.
O corpo vazio foi definido como a diferença entre o peso vivo em jejum e o conteúdo gastrintestinal (Susenbeth \& Keitel, 1988).

O processamento e preparo das amostras foram realizados no Laboratório de Carnes do Instituto de Zootecnia de Nova Odessa, São Paulo. Após o congelamento, sangue/ vísceras e carcaça amostrados foram reduzidos ao estado pastoso utilizando-se um moedor de carne. Quatro amostras da fração sangue/vísceras e da fração carcaça foram retiradas e armazenadas em placas de Petri para serem liofilizadas (Leme et al., 1994; Shields et al., 1993).

A liofilização foi feita em equipamento modelo Stokes, sistema de vácuo a 3 mm Hg de pressão máxima em temperatura inicial inferior a $15^{\circ} \mathrm{C}$ e final de $10^{\circ} \mathrm{C}$, cuja secagem se deu por sublimação. As amostras liofilizadas foram moídas separadamente com gelo seco em liquidificador para posteriores análises, em duplicatas, no Laboratório de Bromatologia do Departamento de Nutrição e Produção Animal da FMVZUSP, Pirassununga. 
Os conteúdos de água, proteína, lipídeo e cinzas foram expressos em porcentagem, na fração vísceras e sangue, na fração carcaça e no corpo vazio. Os dados foram expressos na matéria natural e corrigidos pela MS. A partir da composição química, foram determinadas as taxas de deposição de água, proteína, lipídeo e mineral na carcaça e no corpo vazio ao final do período experimental (11 dias de idade).

A matéria seca considerada foi a liofilizada, porém, a correção dos demais componentes químicos analisados foi realizada por meio da MS obtida em estufa a $105^{\circ} \mathrm{C}$ para evitar erros decorrentes da reabsorção de água durante o processamento das amostras.

Os dados determinados no estudo foram submetidos à análise de regressão por polinômios ortogonais, utilizando-se o pacote computacional SAS (1996).

\section{Resultados e Discussão}

Os valores médios das temperaturas obtidas durante o período experimental foram $29,05^{\circ} \mathrm{C}$ (máxima) e $21,21^{\circ} \mathrm{C}$ (mínima). Os índices pluviométricos e de umidade relativa do ar mantiveram-se dentro dos padrões estimados para a região, não sendo observadas variações climáticas que prejudicassem o desenvolvimento das aves.

Os dados médios de desempenho das aves são apresentados na Tabela 2. Com o aumento do nível de lisina das dietas, verificou-se redução $(\mathrm{P}<0,05)$ linear do peso médio ao final do período ( $\hat{Y}=318,1125-33,9533 X$; $\left.\mathrm{R}^{2}=61,46\right)$, do ganho de peso relativo ( $\hat{\mathrm{Y}}=6,8305-$ 0,7268X; $\left.R^{2}=60,47\right)$, do ganho de peso médio e do consumo médio de ração (Figura 1). Não foram observados efeitos dos níveis de lisina $(\mathrm{P}>0,05)$ sobre a conversão alimentar (Tabela 2).
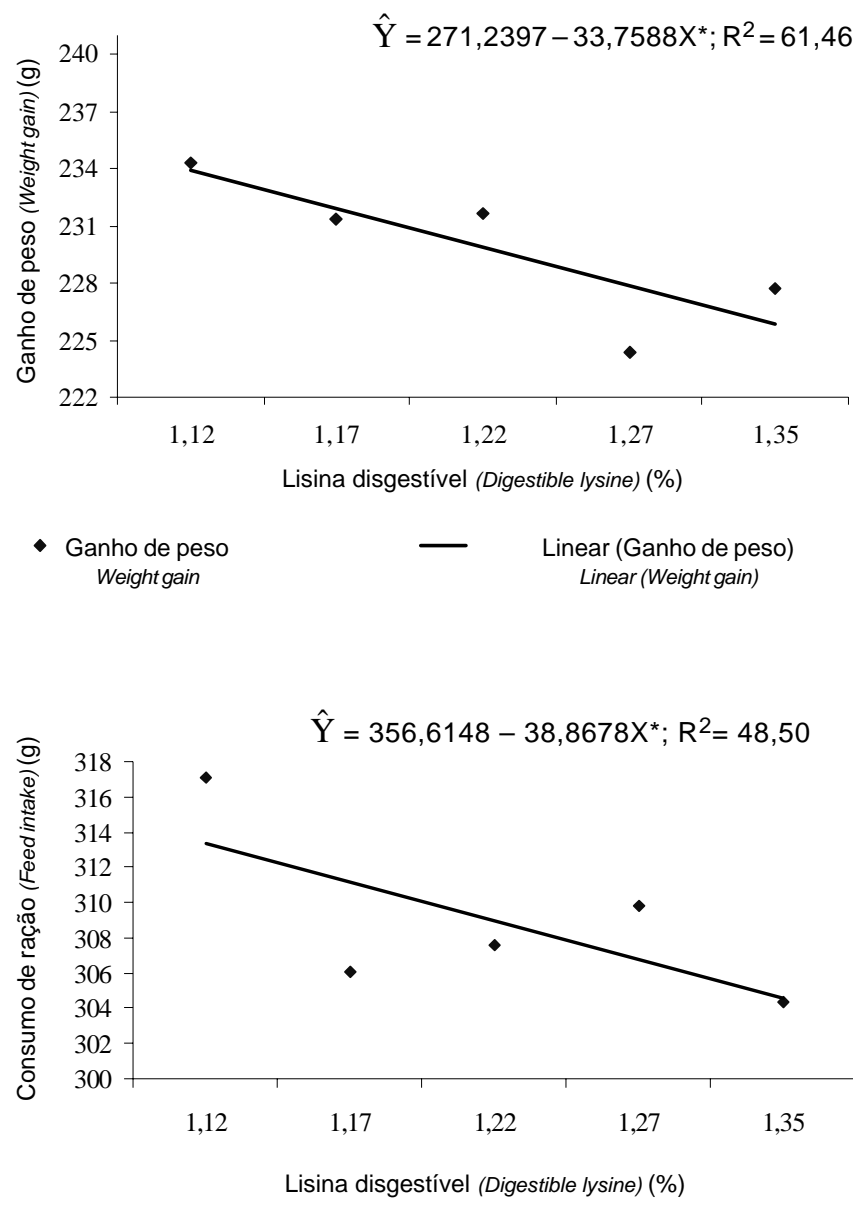

$\begin{array}{ccc}\text { Consumo de ração } & \text { Linear (Consumo de ração) } \\ \text { Feed intake } & \text { Linear (Feed intake) }\end{array}$

Figura 1 - Ganho de peso médio e consumo de frangos de corte machos no período de 1 a 11 dias de idade alimentados com dietas com diferentes níveis de lisina.

Figure 1 - Average weight gain and intake of male broiler chicks from 1 to 11 days old fed diets with different levels of lysine.

Tabela 2 - Desempenho de frangos de corte machos no período de 1 a 11 dias de idade Table 2 - $\quad$ Performance of male broilers from 1 to 11 days old

\begin{tabular}{|c|c|c|c|c|c|c|}
\hline \multirow[t]{2}{*}{ Item } & \multicolumn{5}{|c|}{$\begin{array}{l}\text { Lisina digestível (\%) } \\
\text { Digestible lysine }\end{array}$} & \multirow[t]{2}{*}{$\begin{array}{l}\mathrm{CV} \\
(\%)\end{array}$} \\
\hline & 1,12 & 1,17 & 1,22 & 1,27 & 1,35 & \\
\hline Peso inicial médio(g) (Initial average weight) & 46,7 & 46,6 & 46,4 & 46,6 & 46,7 & - \\
\hline Peso final médio (g) ${ }^{1}$ (Final average weight) & 281,0 & 278,0 & 278,0 & 271,0 & 274,4 & 2,6 \\
\hline Ganho de peso médio (g) ${ }^{1}$ (Average weight gain) & 234,3 & 231,4 & 231,6 & 224,4 & 227,7 & 3,1 \\
\hline Ganho de peso relativo ${ }^{1}$ (Relative weight gain) & 6,03 & 5,98 & 5,98 & 5,82 & 5,89 & 2,5 \\
\hline Ingestão de lisina digestível (g) (Digestible lysine intake) & 3,6 & 3,6 & 3,8 & 3,9 & 4,1 & - \\
\hline Ingestão de EM - kcal (ME intake kcal) & 935,2 & 902,7 & 905,65 & 911,6 & 896,8 & - \\
\hline Relação lisina digestível:Mcal de EM (Digestible lysine:ME mcal ratio) & 3,80 & 3,97 & 4,14 & 4,30 & 4,57 & - \\
\hline Conversão alimentar (Feed:gain ratio) & 1,35 & 1,32 & 1,33 & 1,37 & 1,34 & 2,9 \\
\hline
\end{tabular}

${ }^{1}$ Efeito linear: $(P<0,05)$ (Linear effect). 
A redução no desempenho indica que o aumento da concentração de aminoácidos caracterizou prováveis excessos dietéticos, com prejuízos ao crescimento das aves. O excesso de aminoácidos na dieta ocasiona redução no consumo de alimento. Quando ingeridos e absorvidos em quantidades excessivas, os aminoácidos sobrecarregam as atividades hepática e renal, pois precisam ser desaminados, o que eleva o nível de ácido úrico no sangue.

O gasto energético necessário para catabolizar o excesso dietético dos aminoácidos, no entanto, teria implicações mais significativas sobre a utilização da energia pela ave. Segundo Leclercq (1996) e MacLeod (1997), o custo metabólico da excreção de um aminoácido seria de 6 a 18 moles de ATP, enquanto, para depositá-lo na cadeia protéica, o gasto seria em torno de 4 mol de ATP. A eliminação do aminoácido, portanto, teria alto custo energético e reduziria a utilização de energia na deposição de tecidos, em virtude da necessidade de excreção do nitrogênio.

Além dos prejuízos no desempenho, o excesso de aminoácidos na dieta tem implicações diretas sobre o custo da formulação, em decorrência do elevado preço desta suplementação.

A redução do desempenho com o aumento dietético de lisina indica que, entre os níveis estudados, $1,12 \%$ do aminoácido digestível foi o melhor. Os melhores resultados para peso médio final, ganho de peso médio, ganho de peso relativo e consumo médio de ração, entretanto, não permi- tem sugerir o nível desejável de lisina digestível para frangos de 1 a 11 dias nas condições deste estudo.

A avaliação de níveis mais baixos de lisina poderia elucidar esta resposta se consideradas as condições ocorridas nesta avaliação. Ressalta-se, porém, que Rostagno et al. (2005) sugeriram 1,36\% de lisina digestível para frangos de corte machos, considerados de desempenho superior, no período de 1 aos 7 dias e 1,19\% dos 8 aos 21 dias de idade. Outros estudos realizados na Universidade de Viçosa com pintos de corte Ross machos no período de 1 aos 11 dias de idade indicam que o nível de lisina digestível utilizado para a fase não deve ser inferior a 1,20\% quando as aves são criadas em ambiente limpo e de baixo desafio imunológico (Ajinomoto, 2006).

Resultados encontrados na literatura sugerem níveis inferiores aos aplicados neste estudo. Considerando o desempenho ponderal, Han \& Baker (1991) determinaram em 1,01\% a exigência de lisina digestível para frangos de corte na fase inicial. Segundo Conhalato et al. (1999), em fase similar do crescimento, frangos de corte machos precisam de 1,05\% de lisina digestível para maximizar o ganho de peso e $1,03 \%$ para a melhor conversão alimentar. De acordo com o manual genético da linhagem (Agroceres, 2004) utilizada neste experimento, o nível de lisina digestível recomendado para o período de 0 a 10 dias de idade é de $1,10 \%$, menor que o nível mais baixo testado neste estudo.

De modo semelhante ao observado para o desempenho, o nível 1,12\% de lisina digestível proporcionou os melhores

Tabela 3 - Composição química das frações corporais e de corpo vazio de frangos de corte aos 11 dias de idade Table 3 - Chemical composition of body fractions and empty body of broilers at 11 days of age

\begin{tabular}{|c|c|c|c|c|c|c|}
\hline \multirow[t]{2}{*}{ Item } & \multicolumn{5}{|c|}{$\begin{array}{c}\text { Lisina digestível (\%) } \\
\text { Digestible lysine }\end{array}$} & \multirow[t]{2}{*}{$\begin{array}{l}\text { CV } \\
(\%)\end{array}$} \\
\hline & 1,12 & 1,17 & 1,22 & 1,27 & 1,35 & \\
\hline Sangue e vísceras (g) (Blood and offals) & 67,8 & 65,8 & 66,2 & 65,1 & 66,0 & 4,4 \\
\hline $\begin{array}{l}\text { Peso vivo em jejum (g) }{ }^{1} \text { (Fast live weight) } \\
\text { Sangue e vísceras (Blood and offals) }\end{array}$ & 260,5 & 257,5 & 257,2 & 244,9 & 255,5 & 3,5 \\
\hline Água (\%) (Water) & 80,18 & 79,85 & 79,69 & 79,97 & 80,13 & 0,8 \\
\hline Proteína (\%) (Protein) & 15,07 & 14,98 & 15,59 & 15,65 & 15,31 & 3,6 \\
\hline Lípideo (\%) (Fat) & 3,49 & 3,95 & 3,84 & 3,19 & 3,34 & 19,9 \\
\hline Cinzas $(\%)^{2}($ Ash $)$ & 1,26 & 1,22 & 1,09 & 1,20 & 1,20 & 7,2 \\
\hline \multicolumn{7}{|l|}{ Carcaça (Carcass) } \\
\hline Água (\%) (Water) & 73,91 & 73,52 & 73,36 & 74,03 & 73,94 & 7,3 \\
\hline Proteína (\%) (Protein) & 15,51 & 15,48 & 15,53 & 15,29 & 15,85 & 5,3 \\
\hline Lípideo (\%) (Fat) & 6,57 & 6,96 & 6,82 & 6,85 & 6,27 & 13,1 \\
\hline Cinzas (\%) (Ash) & 3,93 & 4,03 & 4,09 & 3,82 & 3,94 & 9,6 \\
\hline \multicolumn{7}{|l|}{ Corpo vazio (Empty body) } \\
\hline Água (\%) (Water) & 75,59 & 75,14 & 74,82 & 75,60 & 75,57 & 1,0 \\
\hline Proteína (\%) (Protein) & 15,40 & 15,36 & 15,54 & 15,40 & 15,71 & 4,3 \\
\hline Lípideo (\%) (Fat) & 5,77 & 6,19 & 6,16 & 5,88 & 5,49 & 12,8 \\
\hline Cinzas (\%) (Ash) & 3,24 & 3,31 & 3,33 & 3,12 & 3,21 & 8,4 \\
\hline
\end{tabular}

${ }^{1}$ Efeito linear $(\mathrm{P}<0,05)$ (Linear effect).

2 Efeito quadrático $(P<0,01)$ (Quadratic effect). 
resultados para a composição química nas vísceras/sangue e na carcaça/corpo vazio. Não houve respostas significativas para as variáveis estudadas, com exceção da porcentagem de cinzas na fração sangue/vísceras, que apresentou resposta quadrática ( $\hat{\mathrm{Y}}=78,7369-117,3023 \mathrm{X}+47,06146 \mathrm{X}^{2} ; \mathrm{R}^{2}=74,00$ ) aos níveis de lisina estudados, todavia, não é a variável mais indicada para determinação da exigência em lisina das aves.

Os níveis de lisina digestível estudados afetaram $(\mathrm{P}<0,05)$ o peso em jejum e a deposição de água na carcaça (com pés, cabeças e penas). Não foram observadas diferenças nas demais variáveis de deposição química da carcaça e do corpo vazio das aves abatidas aos 11 dias de idade (Tabela 4).

O efeito do nível de lisina sobre o peso vivo de carcaça neste estudo corrobora os resultados encontrados no estudo de desempenho, no qual se obteve resposta linear ( $\hat{Y}=-16.952,0+42302,0 X ; R^{2}=79,00$ ) decrescente para o peso final médio. Semelhante ao peso, a deposição de água na carcaça reduziu linearmente $(\hat{Y}=-10.216,0+25624,0 X$; $\mathrm{R}^{2}=45,00$ ) e esteve relacionada ao ganho de peso corporal, sobretudo nas fases de maior crescimento, quando ocorre maior acúmulo de tecido muscular.

Tabela 4 - Deposição química da carcaça e do corpo vazio de frangos de corte no período de 1 a 11 dias de idade Table 4 - Chemical accretion in carcass and empty body of broilers from 1 to 11 days of age

\begin{tabular}{|c|c|c|c|c|c|c|}
\hline \multirow[t]{2}{*}{ Item } & \multicolumn{5}{|c|}{$\begin{array}{c}\text { Lisina digestível (\%) } \\
\text { Digestible lysine }\end{array}$} & \multirow[t]{2}{*}{$\begin{array}{l}\mathrm{CV} \\
(\%)\end{array}$} \\
\hline & 1,12 & 1,17 & 1,22 & 1,27 & 1,35 & \\
\hline \multicolumn{7}{|l|}{$\begin{array}{l}\text { Deposição carcaça } \\
\text { Carcass accretion }\end{array}$} \\
\hline 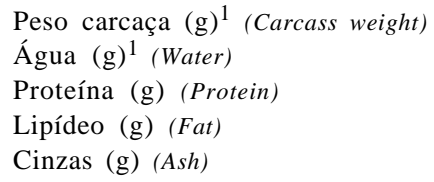 & $\begin{array}{r}192,72 \\
121,46 \\
24,50 \\
10,86 \\
6,46\end{array}$ & $\begin{array}{r}191,68 \\
119,78 \\
24,28 \\
11,59 \\
6,59\end{array}$ & $\begin{array}{r}190,96 \\
118,99 \\
24,24 \\
11,22 \\
7,07\end{array}$ & $\begin{array}{r}179,78 \\
111,95 \\
22,11 \\
10,51 \\
5,77\end{array}$ & $\begin{array}{r}187,70 \\
117,67 \\
24,34 \\
9,99 \\
6,28\end{array}$ & $\begin{array}{r}3,77 \\
4,31 \\
9,00 \\
15,98 \\
14,38\end{array}$ \\
\hline \multicolumn{7}{|l|}{$\begin{array}{l}\text { Deposição total corpo vazio } \\
\text { Total empty body accretion }\end{array}$} \\
\hline $\begin{array}{l}\text { Água (g) (Water) } \\
\text { Proteína (g) (Protein) } \\
\text { Lípideo (g) (Fat) } \\
\text { Cinzas (g) (Ash) }\end{array}$ & $\begin{array}{r}163,47 \\
32,68 \\
12,24 \\
7,12\end{array}$ & $\begin{array}{r}159,98 \\
32,09 \\
13,21 \\
7,20\end{array}$ & $\begin{array}{r}158,99 \\
32,51 \\
13,08 \\
7,62\end{array}$ & $\begin{array}{r}151,67 \\
30,26 \\
11,59 \\
6,34\end{array}$ & $\begin{array}{r}159,60 \\
32,68 \\
11,28 \\
6,90\end{array}$ & $\begin{array}{r}4,20 \\
7,54 \\
16,45 \\
13,04\end{array}$ \\
\hline \multicolumn{7}{|l|}{$\begin{array}{l}\text { Relação } \\
\text { Relation }\end{array}$} \\
\hline $\begin{array}{l}\text { Proteína/água (Protein/water) } \\
\text { Proteína/lipídeo (Protein/fat) }\end{array}$ & $\begin{array}{l}0,20 \\
2,75\end{array}$ & $\begin{array}{l}0,20 \\
2,51\end{array}$ & $\begin{array}{l}0,20 \\
2,54\end{array}$ & $\begin{array}{l}0,20 \\
2,67\end{array}$ & $\begin{array}{l}0,20 \\
2,88\end{array}$ & $\begin{array}{r}5,37 \\
15,00 \\
\end{array}$ \\
\hline
\end{tabular}

${ }^{1}$ Efeito linear $(P<0,05)$ (Linear effect).

\section{Conclusões}

Nas condições deste experimento, a exigência de lisina digestível para frangos de corte machos de 1 aos 11 dias é, no máximo, 1,12\%. Entretanto, níveis inferiores aos avaliados neste estudo devem ser estudados.

\section{Agradecimento}

À Agroceres Ross, à Ajinomoto Biolatina Indústria e Comércio Ltda e à Nutron Alimentos.

\section{Literatura Citada}

AGROCERES [2004]. Manual de manejo de frangos AGROSS. Disponível em: <http://www.agroceresross.com.br/servlet/ navSrvt?cmd=listPublicacaoFrango\&id=47> Acesso em: 14/01/06.

AJINOMOTO. Lisina - Principal aminoácido para deposição protéica. Disponível em: <http://www.lisina.com.br/upload/ bibliografia/AT_02_port.pdf.> Acesso em: 18/01/06.

ASSOCIATION OF OFFICIAL ANALYTICAL CHEMISTS - AOAC. Official methods of analysis. 14.ed. Arlington: 1984. 972p.

BERCOVICI, D.; SUIDA, D. Nutrição protéica de frangos de corte. In: SIMPÓSIO SOBRE NUTRIÇÃO E TECNOLOGIA DE PRODUÇÃO DE RAÇÕES, 1998, Campinas. Anais... Campinas: Colégio Brasileiro de Nutrição Animal, 1998. p.42-54. 
CONHALATO, G.S.; DONZELE, J.L.; ALBINO, L.F.T. et al. Níveis de lisina digestível para frangos de corte machos na fase de 21 a 42 dias de idade. Revista Brasileira de Zootecnia, v.28, n.1, p.91-97, 1999.

DESCHEPPER, K.; DE GROTTE, G. Effect of dietary protein essential and non-essential amino acids on the performance of male broiler chickens. British Poultry Science, v.36, p.229245, 1995.

HAN, Y.; BAKER, D.H. Lysine requirement of fast and slow growing broiler chicks. Poultry Science, v.73, p.1739-1741, 1991.

HURWITZ, S.D.; SKLAN, H.; TALPAZ, H. et al. The effect of dietary level on the lysine and arginine requerimentes of growg chickes. Poultry Science, v.77, p.689-696, 1998.

LECLERCQ, B. Les rejet azote Issus de láviculture: importance et progress envisageables. INRA Production Animal, v.9, p.91101, 1996.

LEME, P.R.; BOIN, C.; ALLEONI, G.F. et al. Estimativa da composição química corporal de novilhos Nelore através do espaço de deutério. Revista da Sociedade Brasileira de Zootecnia, v.23, n.3, p.441-452, 1994.

MACK, S.; BERCOVICI, D.; DE GROOTE, G. et al. Ideal amino acid profile and dietary lysine specification for broiler chickens of 20 to 40 days of age. British Poultry Science, v.40, p.257265, 1999.

McLEOD, M. Effects of amino acid balance and energy: protein ratio on energy and nitrogen metabolismin male broiler chickens. British Poultry Science, v.38, p.405-411, 1997.

PACK, M. Proteína ideal para frangos de corte. Conceitos e posição atual. In: CONFERÊNCIA APINCO DE CIÊNCIA E
TECNOlOGiA AVÍCOLAS, 1995, Curitiba. Anais... Curitiba: Fundação Apinco de Ciência e Tecnologia Avícolas, 1995. p.95-110.

ROSTAGNO, H.S.; ALBINO, L.F.T.; DONZELE, J.L. et al. Composição de alimentos e exigências nutricionais. (Tabelas brasileiras para aves e suínos). Viçosa, MG: Editora UFV, 2005. 186p.

ROSTAGNO, H.S.; SILVA, D.J.; COSTA, P.M.A. et al. Composição de alimentos e exigências nutricionais de aves e suínos. (Tabelas brasileiras). Viçosa, MG: Editora UFV, 2000. 141p.

STATISTICAL ANALYSIS SYSTEM - SAS. SAS user's guide: Statistics. Version 6. Cary: 1996. 956p.

SAKOMURA, N.K.; SILVA, R. Conceitos aplicáveis à nutrição de não ruminantes. Cadernos Técnicos da Escola de Veterinária da UFMG, v.22, p.125-146, 1998.

SHIELDS, R.G.; MAHAN JR., D.C.; GRAHAM, P.L. Changes in swine body composition from birth to $145 \mathrm{~kg}$. Journal of Animal Science, v.57, p.43-54, 1993.

SUSENBETH, A.; KEITEL, K. Partition of whole body protein in different body fractions and some constants in body composition in pigs. Livestock Production Science, v.20, n.1, p.37-52, 1988.

Recebido: 03/04/06 Aprovado: $27 / 02 / 07$ 